\title{
Testing a multi-rotor unmanned aerial vehicle for spray application in high slope terraced vineyard
}

\author{
Daniele Sarri, Luisa Martelloni, Marco Rimediotti, Riccardo Lisci, Stefania Lombardo, Marco Vieri \\ Department of Agricultural, Food and Forestry Systems, University of Florence, Italy
}

\begin{abstract}
Unmanned aerial vehicles (UAVs) are being increasingly used for the spraying of pesticides for crop protection in complex geographic terrains that are not easily accessible by operators. This experiment was conducted to investigate the sprayer performance of a commercial UAV, equipped with different types of nozzles, and compare this new technology with the sprayers usually used on small size mountain vineyards (i.e. a knapsack sprayer and a sprayer gun). Field tests were conducted in a small high slope terraced vineyard. The operative parameters of the sprayers were calculated. Data on droplet coverage, density and size were collected by using water sensitive papers attached with clips to the leaves and analysed. The results showed that the working capacity of the UAV was 2-fold that of the sprayer gun 1.6-fold that of the knapsack sprayer. Droplet coverage, density and size were variable and affected by the position of the targets (water sensitive papers) and the type of sprayer used.
\end{abstract}

Correspondence: Daniele Sarri, Department of Agricultural, Food and Forestry Systems (GESAAF), University of Florence, Piazzale delle Cascine 15, 50144 Florence, Italy.

E-mail: daniele.sarri@unifi.it

Key words: Drone; droplet coverage; unmanned aerial vehicle; precision agriculture; pesticide; unmanned aerial vehicles application in agriculture.

Acknowledgements: this research did not receive any specific grant from funding agencies in the public, commercial, or not-for-profit sectors. The authors would like to acknowledge Dr. Paolo Marras at the Aermatica3D srl., loc. Colverde (Como), Italy for technical support. The authors would also like to thank Dr. Pierpaolo Lorieri and all the staff at the Azienda Vitivinicola Podere Scurtarola (Massa, Italy) for hosting the field experiments.

Received for publication: 7 March 2018.

Accepted for publication: 31 July 2018.

CCopyright D. Sarri et al., 2019

Licensee PAGEPress, Italy

Journal of Agricultural Engineering 2019; L:853

doi:10.4081/jae.2019.853

This article is distributed under the terms of the Creative Commons Attribution Noncommercial License (by-nc 4.0) which permits any noncommercial use, distribution, and reproduction in any medium, provided the original author(s) and source are credited.

\section{Introduction}

In recent years, the rapid development of compact, lightweight and durable sensors and devices has promoted the development of unmanned aerial vehicles (UAVs) used as low altitude remote sensing systems (Zhang and Kovacs, 2012). There are a number of technologies that assist UAVs, e.g. real-time kinematic global navigation satellite systems (GNSS), the geographic information system, aerial photography, multisensory data fusion, real-time image processing, soil mapping, yield monitoring, and variable rate aerial spraying applications following prescription maps (Lan et al., 2017). Recently the European Drones Outlook Study (SESAR, 2016) stated that in the year 2035 would be expected that 90,000 UAVs would be available for delivery activities. A $28 \%$ of the total UAVs will be expected to be involved in chemical spraying and seeding operations (SESAR, 2016). However, the directive 2009/128/EC (European Commission, 2009), which established a framework for Community action to achieve the sustainable use of pesticides, stated that the spraying from UAVs is allowed only in special cases (e.g., no viable alternatives, or there must be clear advantages in terms of reduced impacts on human health and the environment as compared with land-based application of pesticides). An important aim of precision agriculture aviation technologies is a reduction in the use of pesticides while enhancing the application performance. In the last few years, various research projects have been funded by the European Union to improve crop protection stages toward the integration of robotic solutions and UAVs, such as the Robot fleets for Highly Effective Agriculture and forestry management (RHEA) (Vieri et al., 2013; Pérez-Ruiz et al., 2015, Gonzalez-de-Santos et al., 2017) and the Dronebased integrated monitoring system for early detection of crop pathology and pest control in high tech greenhouse agriculture (GIDROM) (GIDROM, 2017) projects. Unmanned agricultural aviation spraying has the advantage of high manoeuvrability and low labour operational costs with no damage to the physical structure of crops or soils due to tractor wheel damage, but also with the disadvantage of generating more drift (Huang et al., 2013). The potential applications of low-volume UAV sprayers consist in operating at low altitudes over crops cultivated in small fields or in complex geographic terrains that are not easily accessible by personnel or ground plant-protection machinery (He et al., 2017; Tirrò et al., 2013). These high landscapes and environmental value cultivation areas of the Mediterranean basin fall within this category such us the vineyards of the Ribeira Sacra of Galicia in Spain, the Douro vineyards in Portugal, the vineyards of Banyuls and Rhône-Alpes in France and the vineyards overlooking the Rhine and Moselle in Germany. In the European Union, this geographical context, better known as heroic viticulture, has been estimated to refer to a total of about 100,000 ha out of a total area covered by viticulture of $8,000,000$ ha (Rieger, 2008). The UAVs application is also suitable for spot spraying within a large crop 
field for highly accurate site-specific operations (Huang et al., 2009). In order to improve the working performance, spraying systems on UAVs should be configured to deliver high-concentration and low-volume sprays. Spray rates for UAV systems are generally 1-2 $\mathrm{L} \mathrm{ha}^{-1}$, which is 25-50 times lower than conventional spray systems. With the small droplets used in low-volume pesticide spraying, UAVs should fly low at a position of 3-5 $\mathrm{m}$ to reduce spray drift (Xue et al., 2016).

The multi-rotor UAVs have many advantages, such as its small size, high flexibility, no requirements for take-off site and driver, frequent take-offs and landings under high temperatures. In addition, it has shown a good performance on hilly terrains, with a complex canopy of trees and even severe turbulence below the UAV rotor (Zhang et al., 2016). The use of battery-powered multirotors (UAVs) for pesticide distribution has been increasing mostly in China. These multi-rotor UAVs have a working capacity of about $20 \mathrm{~m}^{2} \mathrm{~min}^{-1}$ and a liquid tank ranging from 5 to $15 \mathrm{~L}$. Since 1990 in Japan, which is characterised by very small-scale farms, unmanned petrol-powered helicopters have been conventionally used (He et al., 2017).

Results from the collaborations between the China Agricultural University and expert researchers from the US and Germany, have shown that the droplet deposition on plants was influenced by the flight direction, position and crosswind, lead to a weakening of the intensity of the downwash airflow in the direction perpendicular to the ground (He et al., 2017). Baijing et al. (2013) also found that the flight altitude, flight speed and the interaction between the two affected the deposition and uniformity.

As an emerging technology, a series of practical issues in relation to UAV spraying for crop protection remain such us optimal work parameters, poor penetrability into the crop canopy, low droplet coverage, and heterogeneous droplet distribution (Qin et al., 2016). He et al. (2017) highlighted the need for research investigations to optimise the configuration of battery-powered UAV sprayers, such us the right nozzle selection, and improvements in performance (e.g., leaf coverage, canopy penetration, etc.).

Concerning UAVs spraying research results, Zhang et al. (2016) tested a four-rotor UAV sprayer working at a forward speed of $1 \mathrm{~m} \mathrm{~s}^{-1}$ and at three different distances $(0.5,1$ and $1.5 \mathrm{~m})$ between the UAV and the top of the canopy of citrus trees. They found no statistically significantly differences between droplet coverage (\%) and droplet deposition density (droplets $\mathrm{cm}^{-2}$ ) in the different flight positions. Zhang et al. (2016) obtained a percentage leaf coverage of less than $20 \%$, which ranged from 1 to $7 \%$, however the response on citrus tree leaves is not the same as it is with vineyard leaves. Qin et al. (2016) used an UAV at different heights $(0.8$ and $1.5 \mathrm{~m})$ and speeds $\left(3\right.$ and $\left.5 \mathrm{~m} \mathrm{~s}^{-1}\right)$ on a rice crop, but the spray coverage was always lower than 6\%. Mangado et al. (2013) stated that to obtain a biological efficacy on plants, the optimal spray coverage must range from $20 \%$ to $50 \%$.

This research investigated the sprayer performance of a commercial UAV, equipped with different types of nozzles, and compared this new technology with the sprayers used on the farm (i.e., a knapsack sprayer and a sprayer gun). Field tests were conducted in a high slope terraced vineyard. Data on working capacity, droplet coverage, density and volume median diameter were collected and analysed.

\section{Materials and methods}

\section{Experimental set up, design and treatments}

The experiment was conducted in a high slope terraced vineyard located at Massa (central Italy, 44.048035 N, 10.110953 E) (Figure 1). The vineyard was 20-years old, Sangiovese cultivar for wine production, trained to a double horizontal spur-cordon (4-6 per spur) at a $0.5 \mathrm{~m}$ height from the ground, with a planting distance of $2 \times 1 \mathrm{~m}$. It was north-south oriented and located on a hillside (35.4\% of slope) at between 118 and $166 \mathrm{~m}$ above the sea level. The plants had a maximum height of $1.58 \mathrm{~m}$ (1.55 m mean) and width of $0.48 \mathrm{~m}$ at the $\mathrm{BBCH} 75$ growth stage (Lorenz et al., 1995). The terraced arrangement was perpendicular to the gradient lines. The height among terraces was of $0.8 \mathrm{~m}$ and were linked to each other with a $2 \%$ upstream slope. The horizontal distance between rows was $2 \mathrm{~m}$ (Figure 2). The meteorological conditions

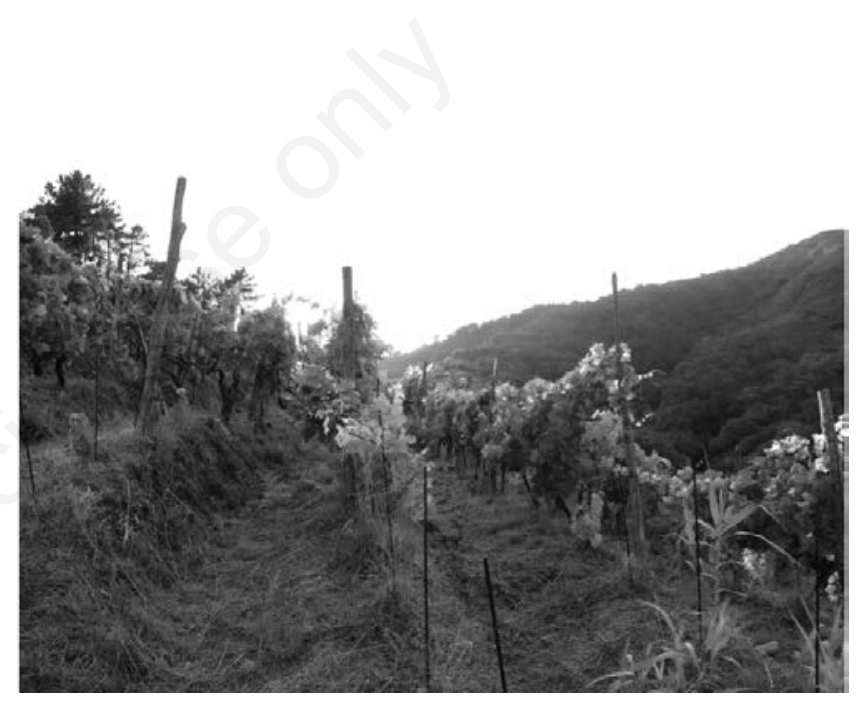

Figure 1. Overview of the sloped terraced vineyard.

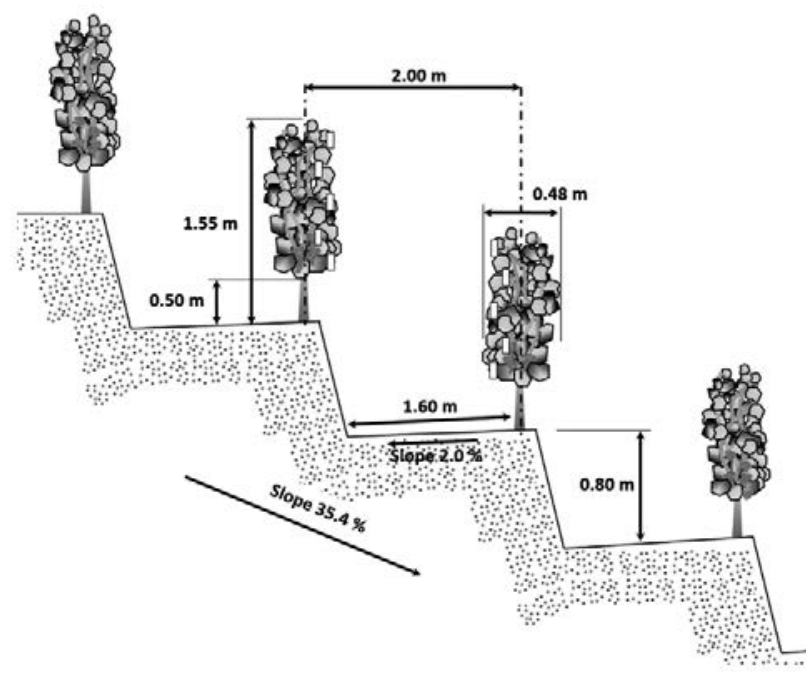

Figure 2. Architecture of terraced mountain vineyard in Massa (central Italy) with heights. Vertical section and layout of the terraces. The test site was simple continuous with an uniform slope. 
of the study area were acquired by the Candia Scurtarola (Massa, Italy) station belonging to the regional monitoring network located at $87 \mathrm{~m}$ from the vineyard under study $(44.046198 \mathrm{~N}, 10.111661$ E). The temperatures ranged from 24 to $26^{\circ} \mathrm{C}$, the average wind speed was $0.78 \mathrm{~m} \mathrm{~s}^{-1}$, and the relative air humidity ranged from $65 \%$ to $70 \%$ (SIR, 2017). The specific meteorological conditions were measured in a row not influenced by the sprayer, close of the experimental vineyard boundary, with a portable Kestrel 5700 Elite Weather Meter (Kestrel Instruments, Boothwyn, PA, USA). The instruments was placed $1 \mathrm{~m}$ above the top of the vineyard canopy for wind direction and velocity measurements. For temperature and relative humidity the sensor was positioned at half the height of the canopy from the ground. Each measure has been replicated three times and the values averaged. The resulting values were $24.7^{\circ} \mathrm{C}$ of temperature, $0.7 \mathrm{~m} \mathrm{~s}^{-1}$ of average wind speed ( $311^{\circ}$ North West oriented) and $68.4 \%$ of relative humidity.

The spraying operation was conducted with a commercial sixrotor UAV sprayer, a sprayer gun and a knapsack sprayer. The settings of the sprayers were reported in Table 1. The UAV was the Bly-c-agri model (AERMATICA3D, Como, Italy). The main flying features of the UAV were reported in Table 2.

The spraying system of the UAV consisted of a 10 L tank, a miniaturised diaphragm pump with a maximum flow rate of $2.8 \mathrm{~L}$ $\mathrm{min}^{-1}$ at $0.42 \mathrm{MPa}$, two nozzle holders with diaphragm check valves placed $1 \mathrm{~m}$ apart, and a solenoid-valve to remotely control the spray activation (Figure 3). An electronic circuit activated both the pump and the solenoid-valve. The working pressure was preliminary checked with a manometer (Wika, class Q 1.6, Milano, Italy) linked directly to nozzle holders during the functioning of the pump. The flow rate was evaluated with a portable digital flow meter (DigE-Check calibrator, Braglia S.r.l., Reggio Emilia, Italy) for all the nozzle used. The flight control system consisted of a flight controller, the A3 model (DJI, Shenzhen, China) which includes an inertial measurement unit, a barometer, a GNSS receiver with an accuracy of $\pm 1.5 \mathrm{~m}$ in the horizontal plane and 0.5 $\mathrm{m}$ in the vertical plane, and a compass for the direction control (Figure 3). The spraying system was connected to the electronic control system to activate spray release based on specific GNSS coordinates and pre-programmed flight plans. Spraying from a UAV following a pre-planned flight route is an important way to ensure the stability of low altitude flights, seamless overlapping of the spraying swath, and consistent spraying quality (Xue et al., 2016). The flight was conducted in a $3000 \mathrm{~m}^{2}$ vineyard.

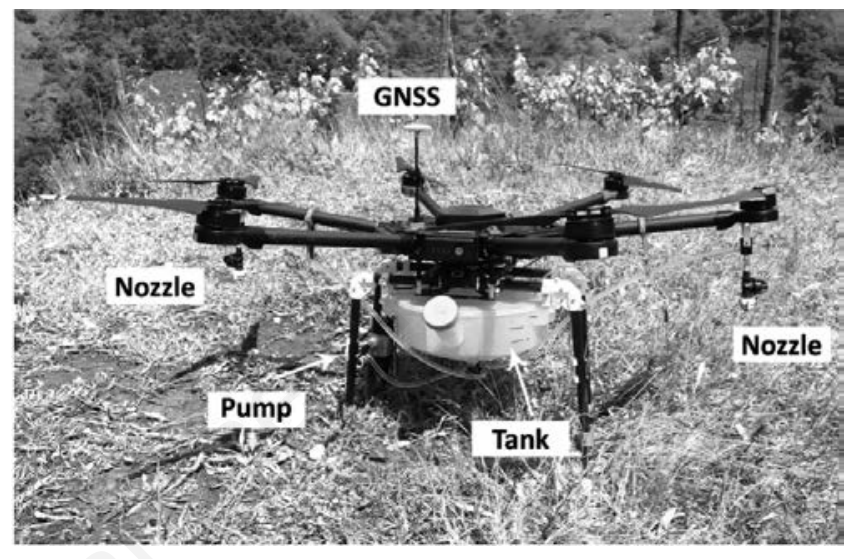

Figure 3. Main devices installed on the unmanned aerial vehicles (Bly-c-agri model) for the spraying operation. At the two sides the nozzle holders with diaphragm check, the pump with solenoid valve and the tank connected to the landing skid. GNSS, global navigation satellite systems.

Table 1. Operative parameters and performance of the unmanned aerial vehicles, sprayer gun and knapsack sprayer.

\begin{tabular}{|c|c|c|c|}
\hline & Six-rotor UAV & Sprayer gun & Knapsack sprayer \\
\hline No. of rotors & Six & Not applicable & Not applicable \\
\hline Nozzle type & $\begin{array}{c}\text { XR8003 TeeJet and } \\
\text { AIXR11003 TeeJet }\end{array}$ & Disc-core type full cone (1.2 mm diameter) & Not calibrated metering knob \\
\hline Height of flight (from the ground) & $5.00 \mathrm{~m}$ & Not applicable & Not applicable \\
\hline Pressure (MPa) & 0.40 & 3.00 & 0.37 \\
\hline Spraying angle & $0^{\circ}$ (vertically down) & From $0^{\circ}$ to $+50^{\circ}$ (First quadrant) & From $0^{\circ}$ to $+50^{\circ}$ (First quadrant) \\
\hline Number of nozzles & 2.00 & 1.00 & 1.00 \\
\hline Theoretical flow rate $\left(\mathrm{L} \mathrm{min}{ }^{-1}\right)$ & 1.36 & 3.40 & 0.54 \\
\hline Effective flow rate $\left(\mathrm{L} \mathrm{min}^{-1}\right)$ & 1.24 & 3.28 & 0.50 \\
\hline Theoretical application rate $\left(\mathrm{L} \mathrm{ha}^{-1}\right)$ & 277.78 & 928.96 & 128.57 \\
\hline Effective application rate $\left(\mathrm{L} \mathrm{ha}^{-1}\right)$ & 253.27 & 896.17 & 119.05 \\
\hline Tank capacity (L) & 10.00 & 1000.00 & 14.00 \\
\hline Spraying pattern & Low volume & High volume & Low volume \\
\hline Working width (m) & 2.50 & 1.00 & 1.00 \\
\hline Forward speed $\left(\mathrm{m} \mathrm{s}^{-1}\right)$ & 0.50 & 0.61 & 0.70 \\
\hline Effective time $\left(\mathrm{h} \mathrm{ha}^{-1}\right)$ & 1.73 & 4.58 & 4.14 \\
\hline Additional time $\left(\mathrm{h} \mathrm{ha}^{-1}\right)$ & 1.86 & 2.90 & 1.66 \\
\hline Operative time $\left(\mathrm{h} \mathrm{ha}^{-1}\right)$ & 3.59 & 7.48 & 5.80 \\
\hline Work chain efficiency (\%) & 49.00 & 61.00 & 71.00 \\
\hline Working productivity (ha $\mathrm{h}^{-1}$ ) & 0.28 & 0.14 & 0.17 \\
\hline
\end{tabular}

UAV, unmanned aerial vehicles. 
The forward speed of the UAV was $0.5 \mathrm{~m} \mathrm{~s}^{-1}$ and the flight height was $5 \mathrm{~m}$ along the maximum gradient line (Figure 4). Preliminary flights were conducted over the row (with nozzles midway between the row), and resulted in not adequate spray coverage, with the majority of the sprayed product accumulated in the centre of the inter-rows. This was probably due to the accuracy provided by a GNSS receiver (which was not provided by the differential corrections) that was not enough to keep a regular straight line. Therefore, the flights were conducted perpendicular relative to the vineyard rows (Figure 4). The distance between the passes ( 3 uphill and 3 downhill) was $2.5 \mathrm{~m}$. The UAV was equipped with two different nozzle types in order to compare the performance of the UAV with different conformations. The two spray nozzles evaluated were the XR8003 (conventional nozzle) and the AIXR11003 (air induction nozzle) (TeeJet, Springfield, USA).

The knapsack sprayer was the Stihl SR 430 (Andreas Stihl AG $\&$ Co, Waiblingen, Germany) (Figure 5A). This consisted of a twostroke engine, a blower that produced an air flow rate of $1300 \mathrm{~m}^{3}$ $\mathrm{h}^{-1}$, a $14 \mathrm{~L}$ tank, a delivery hose and a fan jet baffle screen. A not calibrated metering knob enabled the operator to regulate the flow. This sprayer was based on the pneumatic mist spraying technique, which foresees the use of a low volume application rate achieved by small doses and a high-speed airflow rate, produced from the blower, which pulverise the liquid into droplets and carry to the vineyard leaves. The theoretical application rate was calculated using the flow rate provided by manufacturer of the metering knob, the forward speed of the operator and the plants height. The effective application rate was measured on a surface of $1000 \mathrm{~m}^{2}$, filling the tank with a known volume, and weighing with a scale having a resolution of $0.01 \mathrm{~kg}$. Then the vineyard was sprayed with the same machine setting used for the theoretical application rate, and by subtracting from the original volume the left amount in the tank. The procedure was replicated tree time and the mean value was used. Both in calibration and during experiment the knapsack sprayer was used by the farmer moving forwards in the rows with the sprayer at full throttle.

The sprayer gun was a non-air assisted hand lance sprayer coupled to a high-pressure piston pump AR30 (Annovi Reverberi, Modena, Italy) with a maximum pressure of $4 \mathrm{MPa}$ and flow rate of $36.2 \mathrm{~L} \mathrm{~min}^{-1}$. This sprayer was activated by the PTO of a utility tractor, which also carried a tank with a capacity of $1000 \mathrm{~L}$. A 50 $\mathrm{m}$ long hose was attached to the spray-gun and the pump (Figure $5 \mathrm{~B})$. The pressure losses due to the hose and slope were $0.27 \mathrm{MPa}$. This value was compensated by adjusting the main regulation pressure valve at the final set of $3 \mathrm{MPa}$ measured at the gun. This spraying technology is conventionally referred to as a high volume application rate. The theoretical and effective application rate were calculated following the same procedure of the knapsack sprayer. In order to reduce the measurement errors due to the nozzle usury and load losses, the effective application rate was measured spraying for one minute in a tank and weighting the amount of water sprayed. The pressure was checked with a manometer (Wika, class Q 1.6, Milano, Italy) at the point immediately after the gun.

Both ground sprayers were used with the same spraying technique, which consisted of progressing forwards between the rows by waving the sprayers back and fore with an overlapping pattern over the wine row. The nozzle was always held perpendicular to the plant. The operation started at a height of approximately $1.2 \mathrm{~m}$ $( \pm 0.05)$ which was adjusted according to the sinusoidal movement during the operation. The distance of the sprayer from the plant was $1 \mathrm{~m}( \pm 0.1)$ and the forward speed was $1.26 \mathrm{~m} \mathrm{~s}^{-1}$. There were 1.5 sine waves per meter. The operator sprayed the two side (left and right) of the vineyard canopy. Forward speed was monitored by measuring the time needed to spray each side of a 5 vine sections. The application rates for the knapsack sprayer and the UAVs were calculated according to vineyard canopy area at the BBCH 75 growth stage (Lorenz et al., 1995), while for the sprayer gun was used the volume to spray the experimental plots in a typical manner that would be used to treat the field commercially (Table 1).

The performance of the UAVs, knapsack sprayer and sprayer gun were evaluated in terms of working capacity $\left(\mathrm{ha} \mathrm{h}^{-1}\right)$, droplet

Table 2. Main flying features of the unmanned aerial vehicles.

\begin{tabular}{ll}
\hline Positioning accuracy & Vertical: $\pm 0.5 \mathrm{~m}$; Horizontal: $\pm 1.5 \mathrm{~m}$ \\
Angular speed & Pitch: $300^{\circ} / \mathrm{s} ;$ Yaw: $150 \%$ \\
\hline Maximum angle of pitch & 25 degree \\
Maximum ascending speed & $5 \mathrm{~m} \mathrm{~s}^{-1}$ \\
\hline Maximum descent speed & $3 \mathrm{~m} \mathrm{~s}^{-1}$ \\
Maximum wind resistance & $8 \mathrm{~m} \mathrm{~s}^{-1}\left(2 \mathrm{~m} \mathrm{~s}^{-1}\right.$ at full load $)$ \\
\hline Maximum speed & $17 \mathrm{~m} \mathrm{~s}^{-1}$ \\
Autonomy & $15-20 \mathrm{~min}$ \\
\hline Operating temperature & $-10^{\circ} \mathrm{C}$ to $+40^{\circ} \mathrm{C}$ \\
Automatic fleet scheduling and variable rate distribution using the App BLYCC
\end{tabular}

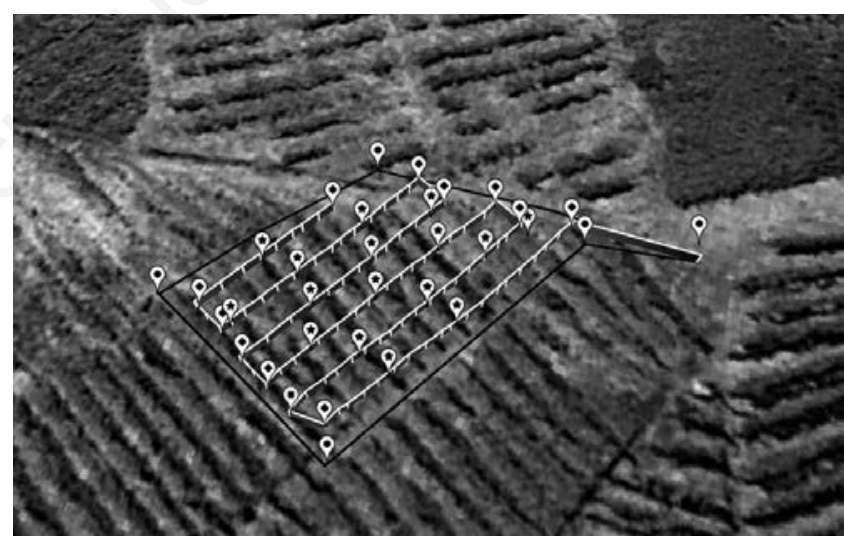

Figure 4. Overview of the interface for the flight plan. The placemarks with points show the borders of the survey flight area, the placemarks with rhombus show where the unmanned aerial vehicles turned, and the placemark with stars, the checking of flight settings.

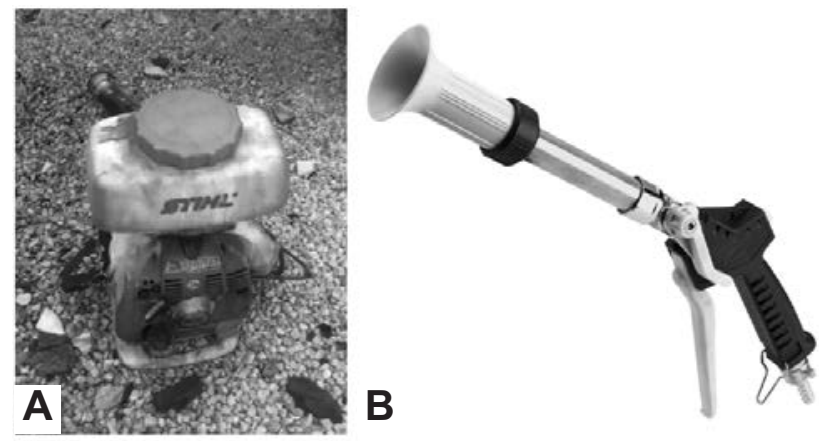

Figure 5. (A) Manual sprayers used during the experiment, the knapsack sprayer (Stihl, SR 430) and (B) the sprayer gun. 
coverage (\%), density (droplets $\mathrm{cm}^{-2}$ ), and volume median diameter (Dv0.5) $(\mu \mathrm{m})$ measured on the water sensitive papers (WSPs) which represented the midpoint droplet size (mean), where half of the volume of the spray is in droplets smaller, and half of the volume is in droplets larger than the mean. The use of WSPs for the spraying characterisation is widely documented in the literature because allows a rapid assessment of spray coverage and deposit (Turner and Huntington, 1970; Holownicki et al., 2002). In addition, recent studies have documented the positively correlation between the spray coverage and the spray characteristics and the amount of deposit on the target in simulated studies (Cerruto and Aglieco, 2013). The experimental design was completely randomised block with four replications. The plots were the vineyard plants. Treatments were replicated four times for each type of sprayer for a total of sixteen.

\section{Data collection}

For the sprayer gun and knapsack sprayer the work chain efficiency of the sprayers were calculated by monitoring the effective, additional and operative times required by the operator to spraying the experimental plots. For the UAVs the work chain efficiency was calculated as above, but the times included the measurements of the numbers of tanks refilling, time for a single refill, time for batteries replacement, and flying times (take-off, time of flight during spraying, landing). The work chain efficiency was used to calculate the working capacity of the sprayers.

WSPs $(26 \times 76 \mathrm{~mm}$, Syngenta Crop Protection AG, Basel, Switzerland) were attached with clips on the outer side of leaves on the external and internal canopy part of the plant. Three WSPs were attached on the external part of the plant in the bottom position, $0.1 \mathrm{~m}$ from the beginning of the vegetation, in the centre at $0.5 \mathrm{~m}$ and at the top at $0.90 \mathrm{~m}$. Two WSPs were attached on the internal part of the plant ( $0.15 \mathrm{~m}$ from the external canopy), at the bottom $(0.3 \mathrm{~m})$ and at the top at $0.7 \mathrm{~m}$ (Figure 6). The WSPs were placed in correspondence of vine with a continuous canopy along the row in order to reduce issues due to the interactions of spray with canopy gaps. For each replication of the treatment WSPs were removed after the application of the water and replaced with clean new ones. The spray solution was water without the addiction of an active ingredient. The WSPs were collected one by one in zip lock bags after spraying and drying. A scanner (Aficio MP4001 PCL6, $\mathrm{RICOH}$, Tokyo, Japan) was then used to acquire images (.tiff) at a 1200 dpi imaging resolution. Droplet coverage (\%), density (droplets $\mathrm{cm}^{-2}$ ) and Dv0.5 $(\mu \mathrm{m})$ were extracted using the digital image processing software ImageJ with the DepositScan plugin following the procedures reported by Zhu et al. (2011). In order to provide a WSPs stains conversion into droplets size, a specific spread factor for each category of droplets generated by the nozzles was used in the WSPs image processing stage, following the procedure provided by Syngenta (2018), Giles and Downey (2003) and Hoffman (2003).

\section{Statistical analysis}

The test of normality of all data was performed using the Shapiro-Wilk normality test. All model specification tests were conducted, i.e., verifications that the mean of the errors was not significantly different from zero using the Student $t$-test, that the errors were normally distributed using the Shapiro-Wilk normality test, homoscedasticity verification using the Breusch-Pagan test, and the serial correlation using the Durbin-Watson test.

Spray coverage data were logit transformed (because the spray coverage is a non-binomial proportion) and then modelled in a linear mixed model using the extension package lmerTest (Kuznetsova et al., 2016) of R statistical software (R Core Team, 2016). Also droplet size data were modelled in a linear mixed model using the same package. Droplets density (which followed a Poisson distribution) were modelled in a generalised linear mixed model using the package lmerTest, which involved a log
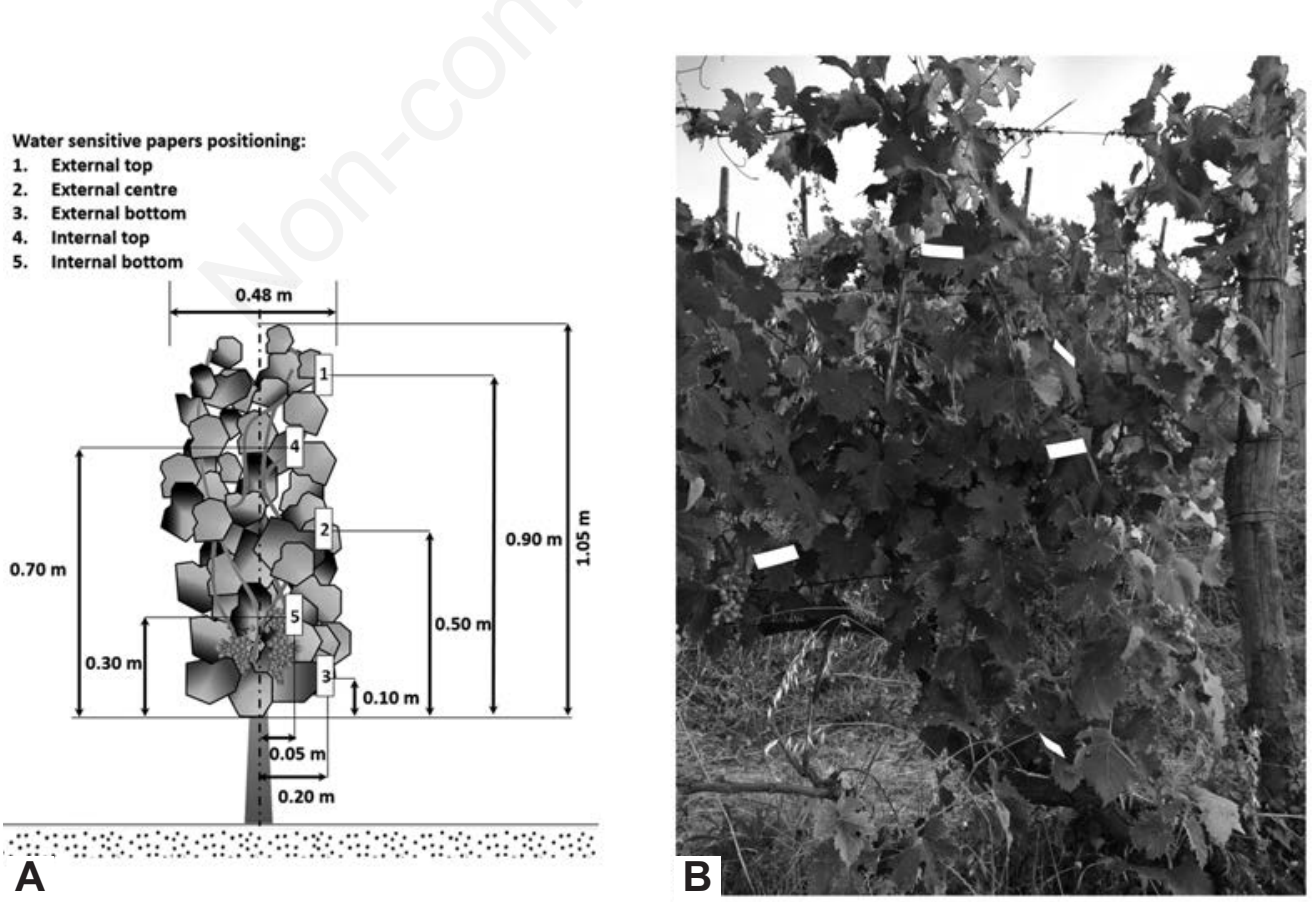

Figure 6. (A) Scheme of water sensitive papers arrangement with dimensions, and average canopy width and (B) their positioning on the plant. 
transformation. In all the models, the type of sprayer and the position of the WSPs were the fixed factors, and the replications were the random factor. To test the effect of the type of sprayer, the position of the WSPs on the plant, and their interaction on the dependent variables (droplet coverage, deposit and size) a mixed ANOVA was computed.

The extension package least-squares means (lsmeans) (Lenth, 2016) of $\mathrm{R}$ was used to compute the least squares means and standard errors of dependent variables, to compute the inverse-transformed values of logit- and log-transformed data, and to plot the graphs of the least squares means. The comparisons between least squares means were computed considering the $95 \%$ confidence interval of the difference between the means of the two groups.

\section{Results and discussion}

The operative parameters and working capacity for the three sprayers were reported in Table 1 . The working capacity of the UAV was 2-fold that of the sprayer gun 1.6-fold that of the knap- sack sprayer, suggesting that the time for spraying was highly reduced compared with the operation conducted by hand-operation. Results of spray coverage are reported in Table 3 . When the WSPs were placed in the external part of the plant, the type of sprayer and the interaction with the position of the WSPs were significant $\left(\mathrm{P}=7.79 \times 10^{-7}\right.$ and $\mathrm{P}=0.02$, respectively). The highest droplet coverage was estimated when the sprayer gun was used (Table 4). This suggests that for high volume applications rate the probability to cover the target is higher then low volume applications, but the risk to encounter to run-off was high. The knapsack sprayer had the same coverage as both UAVs in the top position, whereas in the centre position, the coverage with the knapsack sprayer was higher. At the bottom, the coverage with the knapsack sprayer was higher than the UAV equipped with AIXR11003 nozzles $(95 \%$ CI $-3.59,0.87)$. This was probably due to the fact that the aerial application, realised form UAVs from top to bottom and not tangential, were less effective to create droplets diffusion and reach the lowest part of the plant. Moreover the UAVs technology has nowadays the limit to spraying at maximum working pressure of 0.4 MPa. The low working pressure was responsible of the lim-

Table 3. Least squares means (lsmean) of the spray coverage logit transformed and inverse-transformed values (spray coverage \%) for the different types of sprayers estimated on different positions of the water sensitive papers placed in the external and the internal (evaluation of the penetration) parts of the vineyard plant and comparisons at the $95 \%$ significance level between the lsmeans of the spray coverage.

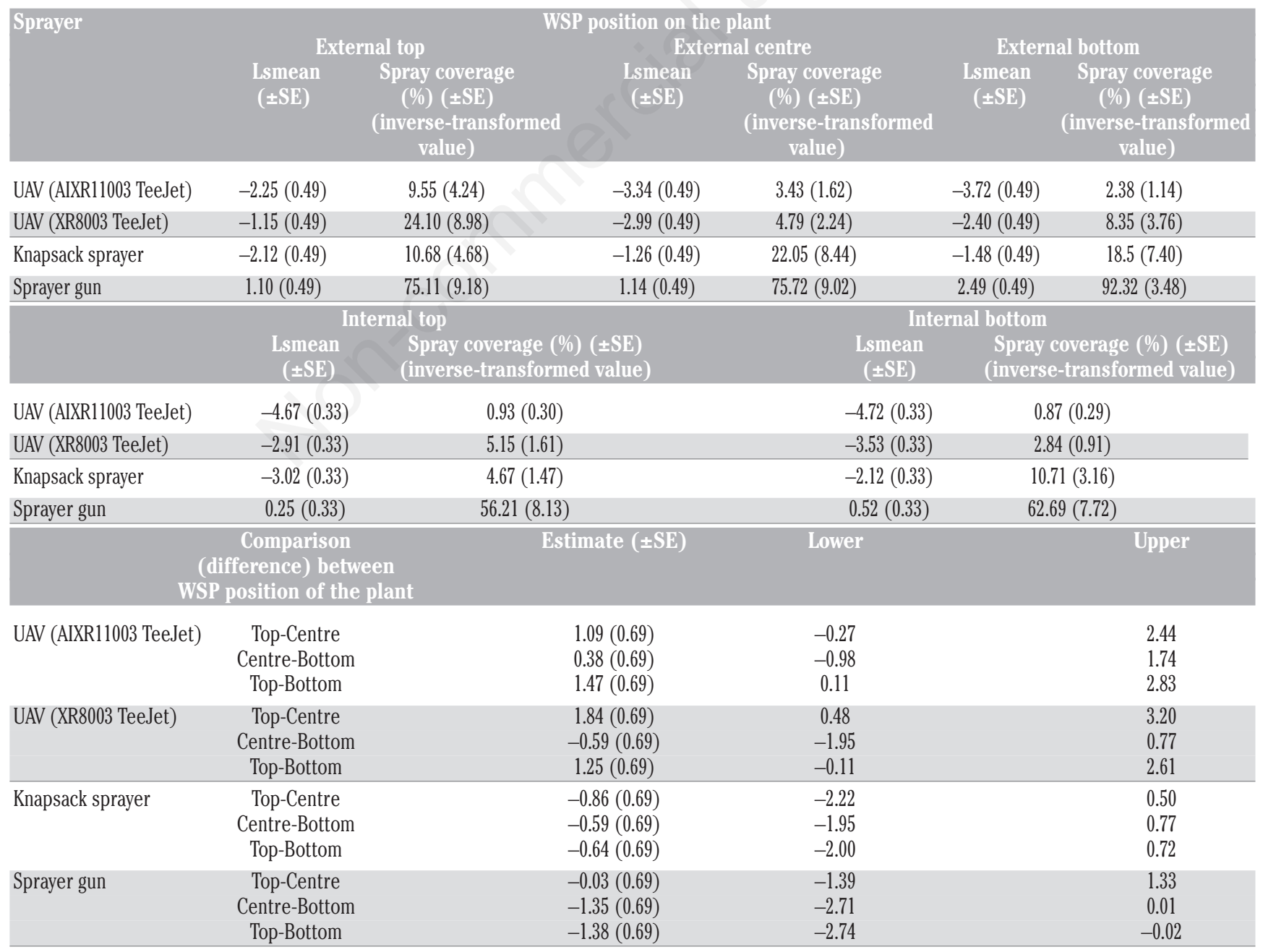

WSP, water sensitive papers; SE, standard error; UAV, unmanned aerial vehicles. 
ited droplets diffusion toward the top of the plant canopy. When the UAV was equipped with AIXR11003 nozzles, the droplet coverage was statistically similar to the UAV with XR8003 nozzles in all the WSPs positions.

For each sprayer, statistical differences were found between the droplet coverage on the WSPs placed in different positions in the external part, with the exception of the knapsack sprayer which uniformly covered the three WSPs placed in the external part of the plant (Table 3). This was probably due to: i) the higher ratio between volume median diameter and number median diameter for the pneumatic technology compared to the other sprayer tested (Vieri, 2003); ii) the presence of the air jet vector; and iii) the shape of the jet. The large fan jet created by the baffle screen of the knapsack sprayer, resulted in a uniformly application even if the operator apply the pesticide forwarding by walking. By using the sprayer gun the fan jet is tighter (even if a high volume was used), and resulted in a not uniform coverage of the external part of plant. Regarding UAVs, the application while flying resulted in a not oriented droplets diffusion which led to a not uniformly coverage of the plants.

When the WSPs were placed in the internal part of the plant to evaluate of the penetration capacity, the WSP position on the plant and the interaction between the type of sprayer and position of the WSP were not significant $(\mathrm{P}=0.56$ and $\mathrm{P}=0.10$, respectively). The type of sprayer affected the spray coverage $\left(\mathrm{P}=6.24 \times 10^{-13}\right)$ and the data were therefore re-modelled by excluding the non-significant factor. Results showed that the sprayer gun gave the highest droplet coverage and the UAV equipped with AIXR11003 nozzles gave the lowest (Table 4). A similar coverage was achieved using the knapsack sprayer and the UAV equipped with the XR8003 noz- zles (Table 4). The use of AIXR11003 nozzles mounted on the UAV significantly reduced the droplet coverage in the internal position of the plant compared with the UAV with XR8003 nozzles (Table 4). The very small coverage values observed when the UAV was equipped with AIXR11003 nozzles (Table 4) suggests that the droplets penetration is quite missing. Probably this could be due to higher Dv0.5 produced by the UAV was equipped with AIXR11003 nozzles, which were carried less effectively compared to smaller droplets (Vieri, 2003). For each sprayer, a representative illustration of the WSPs coverage in the internal and external position of the targets on the plant was reported in Figure 7.

The number of droplets $\mathrm{cm}^{-2}$ in the external part of the plant was affected by the type of sprayer, the WSP position, and their interaction $(\mathrm{P}<0.0001)$. Least squares means values are reported in Table 5 . For each WSP position, the UAV equipped with AIXR11003 nozzles had the lowest number of droplets $\mathrm{cm}^{-2}$, followed by the UAV with XR8003 nozzles, the knapsack sprayer and the sprayer gun, which had the highest number of droplets. The UAV with AIXR11003 nozzles had the same number of droplets in the three WSP positions. The knapsack sprayer produced the same number of droplets $\mathrm{cm}^{-2}$ in the centre and bottom WSP positions, whereas at the top, the number was statistically lower than at centre and bottom position. For the UAV equipped with XR8003 nozzles the number of droplets in the bottom and centre positions were similar, whereas at the top the droplets $\mathrm{cm}^{-2}$ were higher compared with the bottom and centre positions. For the sprayer gun the number of droplets in the top and centre positions were similar, whereas at the bottom the droplets $\mathrm{cm}^{-}$ ${ }^{2}$ were higher compared with the top and centre positions. These results were in accordance with the coverage data.

Table 4. Least squares means (lsmean) of the spray coverage logit transformed and inverse-transformed values (spray coverage \%) for the different types of sprayers estimated in the internal part of the vineyard plant (evaluation of the penetration) and comparisons at the $95 \%$ significance level between the lsmeans of the spray coverage.

\begin{tabular}{lcccccc} 
Sprayer & $\begin{array}{c}\text { Lsmean } \\
( \pm \text { SE) }\end{array}$ & $\begin{array}{c}\text { Spray coverage }(\%)( \pm \text { SE) } \\
\text { (inverse-transformed } \\
\text { value) }\end{array}$ & $\begin{array}{c}\text { Comparisons } \\
\text { (difference) }\end{array}$ & $\begin{array}{c}\text { Estimate } \\
( \pm \text { SE) }\end{array}$ & $\begin{array}{c}\text { Lower } \\
\text { Upper }\end{array}$ \\
UAV (AIXR11003 TeeJet) & $-4.70(0.27)$ & $0.90(0.24)$ & UAV (XR8003 TeeJet) - UAV (AIXR11003 TeeJet) & $1.48(0.38)$ & 0.73 & 2.22 \\
UAV (XR8003 TeeJet) & $-3.22(0.27)$ & $3.83(0.98)$ & Knapsack sprayer - UAV (AIXR11003 TeeJet) & $2.13(0.38)$ & 1.39 & 2.87 \\
\hline Knapsack sprayer & $-2.57(0.27)$ & $7.12(1.77)$ & Sprayer gun - UAV (AIXR11003 TeeJet) & $5.08(0.38)$ & 4.34 & 5.82 \\
Sprayer gun & $0.38(0.27)$ & $59.49(6.44)$ & Knapsack sprayer - UAV (XR8003 TeeJet) & $0.65(0.38)$ & -0.09 & 1.40 \\
\hline & & & Sprayer gun - UAV (XR8003 TeeJet) & $3.61(0.38)$ & 2.87 & 4.35 \\
& & & Sprayer gun - Knapsack sprayer & $2.95(0.38)$ & 2.21 & 3.69 \\
\hline
\end{tabular}

SE, standard error; UAV, unmanned aerial vehicles.
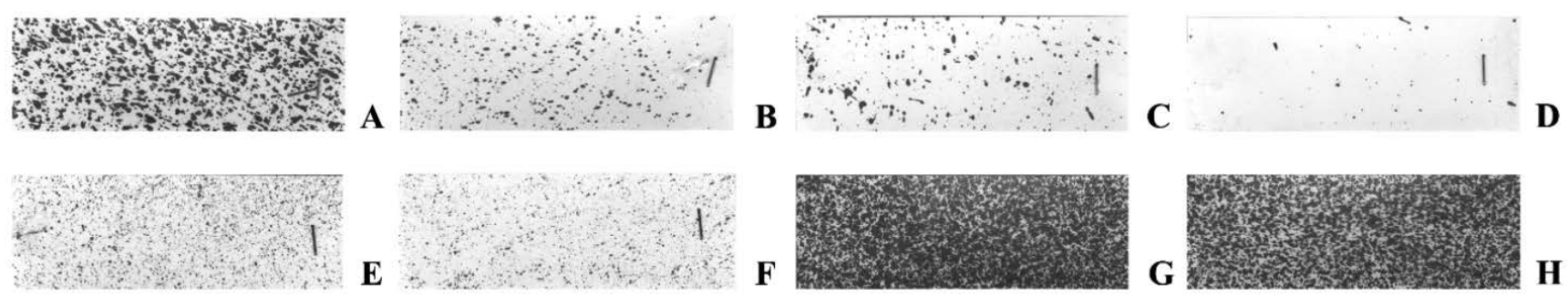

Figure 7. Representative illustration of the water sensitive papers coverage in the internal and external position of the targets on the plant. A) Unmanned aerial vehicles (UAV) XR8003, external part; B) UAV XR8003, internal part; C) UAV AIXR11003, external part; D) AIXR11003, internal part; E) knapsack sprayer, external part; F) knapsack sprayer, internal part; G) sprayer gun, external part; H) sprayer gun, internal part. 
The number of droplets $\mathrm{cm}^{-2}$ in the internal part of the plant was affected by the type of sprayer and the interaction with the WSP position $(\mathrm{P}<0.0001)$, whereas the WSP position was not significant $(\mathrm{P}=0.15)$. Least squares means values are reported in Table 6. Also in the internal part of the plant, in the bottom WSP position, the UAV equipped with AIXR11003 nozzles had the lowest number of droplets $\mathrm{cm}^{-2}$, followed by the UAV with XR8003 nozzles, the knapsack sprayer, and the sprayer gun. In the top position, the UAV with XR8003 nozzles and the sprayer gun had the lowest and highest droplets $\mathrm{cm}^{-2}$, respectively, whereas the UAV with XR8003 nozzles and the knapsack sprayer had a similar number of droplets. Both UAVs had the same droplets $\mathrm{cm}^{-2}$ in the top and bottom WSP positions, whereas when the knapsack sprayer and the sprayer gun were used, the number was higher in the bottom and top positions, respectively. The number of droplets $\mathrm{cm}^{-2}$ measured for both UAVs in the internal and external part of the plant was similar compared with that measured by Zhang et al. (2016), who used a four-rotor UAV equipped with four conical spray nozzles.

Both the coverage and number of droplets $\mathrm{cm}^{-2}$ were evaluated in order to provide a summary of the spraying quality also because they affect directly the biological efficacy. The analysis of this two spray parameters provide useful information about the spray suitability to ensure the higher probability that pest comes into contact with pest and disease. This plays an essential role for non-systemic products. However, To the best of our knowledge, there are not standardised ranges of values providing the optimal spray cover percentages and number of droplets $\mathrm{cm}^{-2}$ for each active ingredient correlated to the biological efficacy of pesticides in vineyards. Only general indications are available (Integrated Crop Protection, 2018; Mangado et al., 2013; Syngenta, 2018). Likewise, as stated by Hewitt (1998) is relevant the evaluation of droplet size through the spectrum analysis. The deposit and transfer of the required

Table 5. Least squares means (lsmean) of the droplets size DV0.5, $(\mu \mathrm{m})$ for the different types of sprayers estimated at different water sensitive paper positions in the external and in the internal (evaluation of the penetration) part of the vineyard plant.

\begin{tabular}{|c|c|c|c|}
\hline Sprayer & $\begin{array}{c}\text { External top } \\
\text { Droplets size Dv0.5 }(\mu \mathrm{m})( \pm \mathrm{SE})\end{array}$ & $\begin{array}{l}\text { WSP position on the plant } \\
\text { External centre } \\
\text { Droplets size Dv0.5 }(\mu \mathrm{m})( \pm \mathrm{SE})\end{array}$ & $\begin{array}{c}\text { External bottom } \\
\text { Droplets size Dv0.5 }(\mu \mathrm{m})( \pm \mathrm{SE})\end{array}$ \\
\hline UAV (AIXR11003 TeeJet) & $257.79(24.22)$ & $294.85(24.22)$ & $283.31(24.22)$ \\
\hline UAV (XR8003 TeeJet) & $202.80(24.22)$ & $218.94(24.22)$ & $240.06(24.22)$ \\
\hline Knapsack sprayer & $115.89(24.22)$ & $98.79(24.22)$ & $96.64(24.22)$ \\
\hline \multirow[t]{2}{*}{ Sprayer gun } & $292.33(24.22)$ & $246.94(24.22)$ & $286.76(24.22)$ \\
\hline & \multicolumn{2}{|c|}{$\begin{array}{c}\text { Internal top } \\
\text { Droplets size Dv0.5 }( \pm \mathrm{SE})\end{array}$} & $\begin{array}{l}\text { iternal bottom } \\
\text { ts size Dv0.5 ( } \pm \text { SE) }\end{array}$ \\
\hline UAV (AIXR11003 TeeJet) & \multicolumn{2}{|c|}{$306.39(38.34)$} & $297.61(38.34)$ \\
\hline UAV (XR8003 TeeJet) & \multicolumn{2}{|c|}{$209.24(38.34)$} & $220.98(38.34)$ \\
\hline Knapsack sprayer & \multicolumn{2}{|c|}{$105.46(38.34)$} & $106.04(38.34)$ \\
\hline Sprayer gun & \multicolumn{2}{|l|}{$282.25(38.34)$} & $341.00(38.34)$ \\
\hline
\end{tabular}

WSP, water sensitive paper; SE, standard error; UAV, unmanned aerial vehicles.

Table 6. Least squares means (lsmean) of the number of droplets $\mathrm{cm}^{-2} \log$ transformed and inverse-transformed values for the different types of sprayers estimated in different positions of the water sensitive paper placed in the external and in the internal (evaluation of the penetration) part of the vineyard plant.

\begin{tabular}{|c|c|c|c|c|c|c|c|}
\hline \multirow[t]{3}{*}{ Sprayer } & \multirow{2}{*}{\multicolumn{5}{|c|}{ WSP position on the plant }} & \multirow{2}{*}{\multicolumn{2}{|c|}{ External bottom }} \\
\hline & & & & & & & \\
\hline & $\begin{array}{l}\text { Lsmean } \\
( \pm \mathrm{SE})\end{array}$ & $\begin{array}{l}\text { Droplets } \mathrm{cm}^{-2} \\
\quad( \pm \mathrm{SE}) \\
\text { (inverse-transformed } \\
\text { value) }\end{array}$ & $\begin{array}{l}\text { Lsmean } \\
( \pm \mathrm{SE})\end{array}$ & $\begin{array}{l}\text { Dr } \\
\text { (inver }\end{array}$ & rmed & $\begin{array}{l}\text { Lsmean } \\
( \pm \mathrm{SE})\end{array}$ & $\begin{array}{l}\text { Droplets } \mathrm{cm}^{-2} \\
( \pm \mathrm{SE}) \\
\text { (inverse-transformed } \\
\text { value) }\end{array}$ \\
\hline UAV (AIXR11003 TeeJet) & $3.09(0.12)$ & $21.92(2.58)$ & $2.93(0.13)$ & & & $2.81(0.13)$ & $16.69(2.20)$ \\
\hline UAV (XR8003 TeeJet) & $4.07(0.09)$ & $58.84(4.81)$ & $3.51(0.10)$ & & & $3.35(0.11)$ & $28.55(3.01)$ \\
\hline Knapsack sprayer & $4.50(0.07)$ & $90.07(6.50)$ & $4.70(0.07)$ & 109 & & $4.77(0.07)$ & $117.68(7.95)$ \\
\hline \multirow[t]{3}{*}{ Sprayer gun } & $4.81(0.07)$ & $122.49(8.20)$ & $4.96(0.06)$ & & & $5.37(0.06)$ & $215.60(12.94)$ \\
\hline & \multicolumn{3}{|c|}{ Internal top } & & \multicolumn{3}{|c|}{ Internal bottom } \\
\hline & \multicolumn{2}{|c|}{$\begin{array}{l}\text { Lsmean } \\
( \pm \text { SE })\end{array}$} & $\begin{array}{l}\text { ts } \mathrm{cm}^{-2}( \\
\text { ransforme }\end{array}$ & lue) & \multicolumn{2}{|c|}{$\begin{array}{l}\text { Lsmean } \\
( \pm \mathrm{SE})\end{array}$} & $\begin{array}{l}\text { Droplets } \mathrm{cm}^{-2}( \pm \mathrm{SE}) \\
\text { erse-transformed value) }\end{array}$ \\
\hline UAV (AIXR11003 TeeJet) & \multicolumn{2}{|c|}{$2.58(0.22)$} & $13.24(2.88)$ & & \multicolumn{2}{|c|}{$2.11(0.24)$} & $8.27(1.99)$ \\
\hline UAV (XR8003 TeeJet) & \multicolumn{2}{|c|}{$3.30(0.19)$} & $27.14(5.27)$ & & \multicolumn{2}{|c|}{$3.48(0.19)$} & $32.35(6.17)$ \\
\hline Knapsack sprayer & \multicolumn{2}{|c|}{$3.38(0.19)$} & $29.35(5.66)$ & & \multicolumn{2}{|c|}{$4.04(0.18)$} & $56.98(10.37)$ \\
\hline Sprayer gun & \multicolumn{2}{|c|}{$5.95(0.17)$} & $382.97(65.71)$ & & \multicolumn{2}{|c|}{$5.18(0.17)$} & $177.94(30.90)$ \\
\hline
\end{tabular}

WSP, water sensitive paper; SE, standard error; UAV, unmanned aerial vehicles. 
Table 7. Least squares means (lsmean) of the droplet size $(\mu \mathrm{m})$ for the different types of sprayers estimated in the external and internal part of the vineyard plant and comparisons at the $95 \%$ significance level between the lsmeans of the droplet size.

\begin{tabular}{|c|c|c|c|c|c|}
\hline Sprayer & $\begin{array}{l}\text { Droplets size Dv0.5 }(\mu \mathrm{m}) \\
( \pm \mathrm{SE})\end{array}$ & $\begin{array}{l}\text { External part of the plant } \\
\text { Comparisons (difference) }\end{array}$ & Estimate & $\begin{array}{l}\text { Lower } \\
( \pm \text { SE) }\end{array}$ & Upper \\
\hline UAV (AIXR11003 TeeJet) & $278.65(17.65)$ & UAV (AIXR11003 TeeJet) - UAV (XR8003 TeeJet) & $58.05(24.96)$ & 9.13 & 106.97 \\
\hline UAV (XR8003 TeeJet) & $220.60(17.65)$ & UAV (AIXR11003 TeeJet) - Knapsack sprayer & $174.88(24.96)$ & 125.96 & 223.80 \\
\hline Knapsack sprayer & $103.77(17.65)$ & UAV (AIXR11003 TeeJet) - Sprayer gun & $3.305(24.96)$ & -45.62 & 52.23 \\
\hline \multirow[t]{3}{*}{ Sprayer gun } & $275.34(17.65)$ & UAV (XR8003 TeeJet) - Knapsack sprayer & $116.83(24.96)$ & 67.91 & 165.75 \\
\hline & & Sprayer gun - UAV (XR8003 TeeJet) & $54.74(24.96)$ & 5.82 & 103.66 \\
\hline & & Sprayer gun - Knapsack sprayer & $171.57(24.96)$ & 122.65 & 220.49 \\
\hline Sprayer & $\begin{array}{l}\text { Droplets size Dv0.5 ( } \mu \mathrm{m}) \\
( \pm \mathrm{SE})\end{array}$ & $\begin{array}{l}\text { Internal part of the plant } \\
\text { Comparisons (difference) }\end{array}$ & Estimate & $\begin{array}{l}\text { Lower } \\
( \pm \text { SE) }\end{array}$ & Upper \\
\hline UAV (AIXR11003 TeeJet) & $302.00(32.43)$ & UAV (AIXR11003 TeeJet) - UAV (XR8003 TeeJet) & 86.89 & -2.99 & 176.78 \\
\hline UAV (XR8003 TeeJet) & $215.11(32.43)$ & UAV (AIXR11003 TeeJet) - Knapsack sprayer & 196.25 & 106.36 & 286.13 \\
\hline Knapsack sprayer & $105.75(32.43)$ & UAV (AIXR11003 TeeJet) - Sprayer gun & -9.63 & -99.51 & 80.26 \\
\hline \multirow[t]{3}{*}{ Sprayer gun } & $311.63(32.43)$ & UAV (XR8003 TeeJet) - Knapsack sprayer & 109.36 & 19.47 & 199.24 \\
\hline & & Sprayer gun - UAV (XR8003 TeeJet) & 96.52 & 6.63 & 186.40 \\
\hline & & Sprayer gun - Knapsack sprayer & 205.87 & 115.99 & 295.76 \\
\hline
\end{tabular}

SE, standard error; UAV, unmanned aerial vehicles.

dose to the target achieved with the proper droplets dimensioning allows to perform spraying with reduced off-target losses thus drift and more in general high spray efficacy (Hewitt et al., 1998).

The size of the droplets $(\mu \mathrm{m})$ in the external and internal part of the plant was only affected by the type of sprayer $\left(\mathrm{P}=1.6010^{-4}\right.$ and $\mathrm{P}=2.410^{-3}$, for the external and internal part of the plants, respectively). The WSP position and the interaction were not significant $(\mathrm{P}=0.69$ and $\mathrm{P}=0.46$ for the WSP position; $\mathrm{P}=0.43$ and $\mathrm{P}=0.67$ for the interaction, for the external and internal part of the plants respectively). Least squares means of the size are reported in Table 5. Data were re-modelled by excluding the non-significant factor. Results showed that the UAV equipped with AIXR11003 nozzles and the sprayer gun had the largest droplets, whereas the knapsack sprayer produced the smallest (Table 7). In the external part of the plant, the UAV with XR8003 nozzles had smaller droplets compared with the UAV equipped with AIXR11003 nozzles, whereas in the internal part of the plant, the size of the droplets of both UAVs was similar (Table 7), but this was due to the high standard errors estimated. This suggests that there was a very high variability in the dimension of droplets on the WSPs.

\section{Conclusions}

This research represents a first step in the application of UAV sprayer in high slope terraced vineyards. They also could be used in all the cases that European legislation allowed their use, i.e. where there are no viable alternatives to the use of aerial spraying. Generally the low coverage resulted from the experiment indicated that this technology is still at its early stage for spraying applications and technical weakness have to be resolved. This are mainly represented by the low working pressure, the too high distance between the nozzles and the plants that currently cannot be reduced due to technical flight limits at lower heights, and the absence of a conveyor to the air jet toward the canopy of the plant. At this stage of the development of the technology, an actual use of the UAVs could be represented by the spraying of insecticidal bait or for the spreading of products in granular form (e.g. pupae of Trichogramma Maidis (Pint. et Voeg.) vs Ostrinia nubilalis (Hübner), where is required only that the baits or the granules reach the target, independently of the leaves coverage percentage. Further studies in order to improve the spraying performance of the UAV should be needed due to the fact of the increase of the working capacity, timely of the applications, and effort for operators compared to the ordinary manual sprayers used in this context.

\section{References}

Baijing Q., Liwei W., Donglin., Jianhao W., Guorong D., Xianping G. 2012. Effects of flight altitude and speed of unmanned helicopter on spray deposition uniform. Trans. Chinese Soc. Agric. Engine. 29:25-32.

Cerruto E., Aglieco C. 2013. Water sensitive papers simulation to assess deposits on targets. J. Agricult. Engine. 44:397-401.

European Commission. 2009. Directive 2009/128/EC of the European Parliament and of the Council of 21 October, establishing a framework for Community action to achieve the sustainable use of pesticides. Official Journal of the European Union, 71-86. L 30924/11/2009.

GIDROM. 2017. CORDIS. Community Research and Development Information Service. Available from: http://cordis.europa.eu/project/rcn/198912_en.html Accessed: 26 September 2017.

Giles D.K., Downey D. 2003. Quality control verification and mapping for chemical application. Precision Agric. 4:103 $\square 24$.

Gonzalez-de-Santos P., Ribeiro A., Fernandez-Quintanilla C., Lopez-Granados F., Brandstoetter M., Tomic S., Pedrazzi S., Peruzzi A., Pajares G., Kaplanis G., Perez-Ruiz M., Valero C., Del Cerro J., Vieri M., Rabatel G., Debilde B. 2017. Fleets of robots for environmentally-safe pest control in agriculture. Precision Agric. 18:574-614. 
He X., Bonds J., Herbst, A., Langenakens J. 2017. Recent development of unmanned aerial vehicle for plant protection in East Asia. Int. J. Agricult. Biol. Engine. 10:18-30.

Hewitt A.J., Valcore D.L., Teske M.E., Schick R.J. 1998. Droplet size classification for agricultural sprays. Proc. Ilass 11th Annual Conf. Liquid Atomization and Spray Systems, Sacramento, CA, USA, pp 55-59.

Hoffman W.C. 2003. Field swath and drift analyses techniques. ASAE Paper No. AA03 $\square 007$. ASAE, St. Joseph, MI, USA.

Holownicki R., Doruchowski G., Swiechowski W., Jaeken P. 2002. Methods of evaluation of spray deposit and coverage on artificial targets. Electronic J. Polish Agric. Univ. 5:1-9.

Huang Y., Hoffmann W.C., Lan Y., Wu W., Fritz BK. 2009. Development of a spray system for an unmanned aerial vehicle platform. Appl. Engine. Agricult. 25:803-9.

Huang Y., Thomson S.J., Hoffmann W.C., Lan Y., Fritz B.K. 2013. Development and prospect of unmanned aerial vehicle technologies for agricultural production management. Int. J. Agric. Biol. Engine. 6:1-10.

Integrated Crop Protection. 2018. Spray application basics. Available from:http://www.tfga.com.au/index.php/download_file/view/105/ 480/Spray_Application_Basics_LR.PDF?file=Spray_Application Basics LR.PDF Accessed: 25 September 2018.

Kuznetsova A., Brockhoff P.B., Christensen R.H.B. 2016. lmerTest: tests in linear mixed effects models. $\mathrm{R}$ package version 2.0-32. Available from: https://CRAN.R-project.org/package=lmerTest Accessed: 26 September 2017.

Lan Y., Shengde C., Fritz B.K. 2017. Current status and future trends of precision agricultural aviation technologies. Int. J. Agric. Biol. Engine. 10:1-17.

Lenth R.V. 2016. Least-squares means: the R package lsmeans. J. Stat. Software 69:1-33.

Lorenz D., Eichorn D., Bleiholder H., Klose R., Meier U., Weber E. 1995. Growth Stages of the Grapevine: Phenological growth stages of the grapevine (Vitis vinifera L. ssp. vinifera) - Codes and descriptions according to the extended $\mathrm{BBCH}$ scale. Australian J. Grape Wine Res. 49:66-70.

Mangado J., Arazuri S., Arnal P., Jarén C., López A. 2013. Measuring the accuracy of a pesticide treatment by an image analyzer. Procedia Technol. 8:498-502.

Pérez-Ruiz M., Gonzalez-de-Santos P., Ribeiro A., FernandezQuintanilla C., Peruzzi A., Vieri M., Tomic S., Agüera J. 2015. Highlights and preliminary results for autonomous crop protection. Comput. Electron. Agricult. 110:150-61.

Qin W.C., Qiu B.J., Xue X.Y., Chen C., Xu Z.F., Zhou Q.Q. 2016. Droplet deposition and control effect of insecticides sprayed with an unmanned aerial vehicle against plant hoppers. Crop Prot. 85:79-88.

R Core Team 2016. R: A language and environment for statistical computing. R Foundation for Statistical Computing, Vienna, Austria. Available from: https://www.R-project.org/ Accessed: 26 September 2017.

Rieger T. 2008. Mountain viticulture in Europe, part two. Vineyard Wine. Manage. 1:112-9.

SESAR 2016. European Drones Outlook Study Unlocking the value for Europe. Available from: https:/www.sesarju.eu/sites/ default/files/documents/reports/European_Drones_Outlook_S tudy_2016.pdf Accessed: 23 July 2018.

Syngenta. 2018. Water-sensitive paper for monitoring spray distribution. Available from: https://www.qinstruments.de/uploads/ media/wsp_use-it-in-agriculture.pdf Accessed: 25 July 2018.

SIR. 2017. Servizio Idrico Regionale, Regione Toscana meteo station TOS11000027 Candia Scurtarola. Available from: http://www.sir.toscana.it/ricerca-dati Accessed: 21 June 2017 [In Italian].

Tirrò G., Lisci R., Rimediotti M., Sarri D., Vieri M. 2013. The cross-border project between France and Italy MARS+. subproject - innovative technologies for the mechanisation of the areas hard to reach. J. Agricult. Engine. 44:425-30.

Turner C., Huntington K. 1970. The use of water-sensitive dye for the detection and assessment of small spray droplets. J. Agric. Eng. Res. 15:385 $\square 7$.

Xue X., Lan Y., Sun Z., Chang C., Hoffmann W.C. 2016. Develop an unmanned aerial vehicle based automatic aerial spraying. Comput. Electron. Agricult. 128:58-66.

Vieri M. 2003. La distribuzione dei fitofarmaci: i criteri. In: P. Balsari, A. Scienza (Ed.), Forme di allevamento della vite e modalità di distribuzione dei fitofarmaci Bayer CropScience, Milano, Italy. Inf. Agrario 160-93. [In Italian]

Vieri M., Sarri D., Rimediotti M., Perria R., Storchi P. 2013. The new architecture in the vineyard system management for variable rate technologies and traceability. ActaHortic. 978:47-53.

Zhang P., Deng L., Lyu Q., He S., Yi S., Liu Y., Yu Y., Pan H. 2016. Effects of citrus tree-shape and spraying height of small unmanned aerial vehicle on droplet distribution. Int. J. Agric. Biol. Engine. 9:45-52.

Zhang C., Kovacs J.M. 2012. The application of small unmanned aerial systems for precision agriculture: a review. Precision Agric. 13:693-712.

Zhu H., Salyani M., Fox R.D. 2011. A portable scanning system for evaluation of spray deposit distribution. Comput. Electron. Agric. 76:38-43. 